\title{
Uso do aparelho de Thurow no tratamento da má oclusão esquelética de Classe II
}

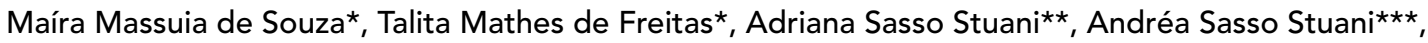 \\ Maria Bernadete Sasso Stuani ${ }^{\star \star \star \star}$
}

\section{Resumo}

O objetivo deste trabalho foi realizar uma revisão de literatura em relação ao tratamento da má oclusão esquelética de Classe II com a utilização do splint maxilar removível associado à tração alta, realçando sua influência no crescimento ósseo e seus benefícios. Através do relato do caso clínico será mostrada a confecção e os efeitos do aparelho de Thurow quando utilizado no período da dentadura mista, para a correção da Classe II esquelética.

Palavras-chave: Classe II. Tração alta. Splint maxilar.

\section{INTRODUÇÃO}

As relações ântero-posteriores anormais das bases ósseas correspondem a cerca de dois terços das anomalias presentes nos pacientes ortodônti$\cos ^{7}$. Nestes casos, a correção da má oclusão, com apenas movimento dental, é indesejável, já que os dentes serão posicionados em desequilíbrio neuromuscular. A melhor escolha seria a correção da desarmonia esquelética dos arcos dentários ${ }^{10}$.

A Classe II é caracterizada pela posição mandibular distal ao maxilar, cuja má relação pode ser causada por displasia óssea ou por movimento anterior do arco superior e do processo alveolar, ou pela combinação dos fatores esqueléticos e dentários. A sobressaliência é excessiva na Classe II, divisão 1, e a mordida é provavelmente profunda. Tipicamente existe uma hiperatividade do múscu- lo mentoniano, o qual se contrai fortemente, elevando o músculo orbicular dos lábios, para efetuar o selamento labial ${ }^{15}$. Anormalidades na forma e atividade da musculatura orofacial contribuem para acentuar e perpetuar esta má oclusão, pelos seus efeitos sobre o desenvolvimento da dentição².

Em muitos casos, a má oclusão de Classe II requer o movimento distal dos dentes superiores posteriores. Com esse objetivo, um grande número de procedimentos foi proposto, os quais podem ser divididos basicamente em dois tipos: 1) mecanismos ortodônticos desenhados para movimentação dentária e 2) mecanismos ortopédicos que posicionam distalmente o complexo maxilar tanto por "manipulação do crescimento", quanto por movimentação distal deste complexo ${ }^{4}$.

O tratamento para a relação ântero-posterior

* Estagiária da Disciplina de Ortodontia Preventiva da Universidade de São Paulo, em Ribeirão Preto FORP - USP.

** Especialista em Radiologia e Mestranda em Odontopediatria na Universidade de São Paulo, em Ribeirão Preto - FORP - USP.

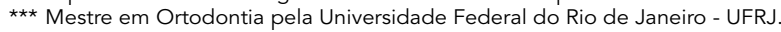

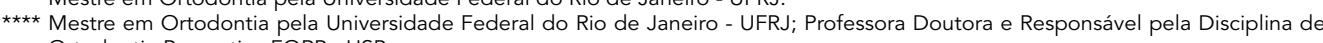
Ortodontia Preventiva FORP - USP. 
anormal entre a maxila e mandíbula está diretamente dirigido à inibição do crescimento anterior da maxila. Nas situações onde a mandíbula se encontra retruída, a melhor alternativa seria permitir ou estimular o crescimento anterior deste arco, favorecendo a normalização do relacionamento sagital intermaxilar nos casos de Classe II com discrepância ósseo dentária severa ou com ângulo ANB elevado ${ }^{10}$.

Para o tratamento eficaz da má oclusão esquelética de Classe II não basta promover apenas um rearranjo nas posições e inclinações dentárias mas, principalmente, agir sobre as bases ósseas. Isto permitiria alcançar tanto uma oclusão ideal e estável quanto um perfil agradável e bem balanceado ${ }^{25}$. Quando esta má oclusão é conseqüência da protrusão da base óssea maxilar, é correto pensar em restringir os movimentos do arco superior durante o crescimento para obter um equilíbrio com a mandíbula. Para isto é indicado o uso do aparelho extrabucal (AEB) no arco maxilar, que pode ser usado individualmente ou combinado com aparelho removível ${ }^{22}$.

Há um consenso, com base em investigações clínicas, de que forças aplicadas sobre a maxila em faces em crescimento, resultariam num maior posicionamento distal em relação à base craniana. Uma vez que a maioria dos pacientes com má oclusão de Classe II tem algum tipo de desarmonia esquelética, o tratamento precoce (pré-adolescência) é desejado, com o objetivo de modificar o crescimento dos arcos. Esta fase de tratamento é quase sempre seguida de uma segunda, mais simples, com movimentação dentária durante a adolescência ${ }^{8,12,13,17,18,20,23,28 .}$.

Woodside ${ }^{29}$ demonstrou que, durante o período da dentadura mista, pelo menos metade das crianças passa por um pico de crescimento, e mesmo que não haja uma mudança abrupta na velocidade de crescimento, este ainda assim é mantido num nível de pelo menos 50\% relacionado a mudanças pré-puberais.

A indicação de um tratamento precoce deve-se também ao fato da presença de um desvio funcional ser capaz de produzir efeitos prejudiciais ao desenvolvimento craniofacial. A normalização do relacionamento oclusal facilita o modelamento dentoalveolar compensando a desarmonia do padrão de crescimento dos $\operatorname{arcos}^{3}$. Um melhor entendimento da inter-relação dos componentes de crescimento vertical e sagital constitui uma condição prévia ao planejamento de um ajuste sobre o padrão de crescimento. $\mathrm{O}$ desenvolvimento sagital da mandíbula é parcialmente dependente de seu desenvolvimento vertical, podendo, portanto, ser melhorado por um controle vertical na região de molares. Isto pode ser conseguido pelo uso da tração alta adaptada nos primeiros molares superiores e ativadores com plano de mordida ou, como sugerido por Thurow ${ }^{23}$, por um splint maxilar associado à tração alta posterior ${ }^{3}$.

O aparelho extrabucal tradicional é acoplado em bandas ortodônticas nos molares superiores, entretanto, Thurow ${ }^{23}$ salientou que o uso destes dentes como ponto de aplicação da força do extrabucal poderia gerar inclinação vestibular ou palatina, dependendo do tipo de tração utilizada, cervical ou occipital, além do efeito ser predominantemente dentário com inclinação distal do primeiro molar superior. Este autor propôs então, um aparelho extrabucal acoplado a uma placa de acrílico com cobertura oclusal de todos os dentes superiores irrompidos, que ele denominou de splint maxilar, tendo como vantagem a possibilidade de ajustes ortodônticos posteriores, evitando-se extrações ou cirurgias ortognáticas ${ }^{6,21,23}$.

\section{CONFECÇÃO DO APARELHO DE THUROW}

Thurow $^{23}$ descreveu um aparelho para o tratamento da má oclusão esquelética de Classe II,

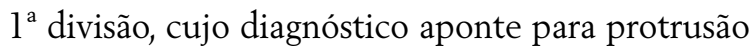
maxilar ou dentoalveolar. Consiste em um splint maxilar que promove uma área de aplicação de força potencialmente ampla. Este é confeccionado em resina acrílica autopolimerizável, que cobre a superfície oclusal e as superfícies palatinas e vestibulares em dois terços de todos os dentes superiores irrompidos, e um arco extrabucal que é 
posicionado sobre a superfície oclusal e incisal dos dentes superiores. Este aparelho é rígido e proporciona controle em massa de todos os dentes em todas as direções, inclusive mésio-distalmente. A superfície acrílica oclusal desoclui os dentes eliminando as interferências oclusais durante o período de aplicação da força, o que não só facilita a movimentação dos dentes superiores, mas também permite a correção das displasias funcionais mandibulares.

$\mathrm{O}$ arco externo deve ser inclinado na direção aproximada ao centro de resistência da maxila, minimizando a rotação da mesma e, ao mesmo tempo, proporcionando uma retenção adequada para o $\operatorname{splin} t^{23}$. Esta rotação é reduzida quando a inclinação do arco externo, que deve ser encurtado no nível do primeiro molar permanente, for de preferencialmente 45 graus acima do plano oclusal, associado a uma tração alta posterior, sendo a força dirigida para o centro de resistência da maxila, e as forças compressivas direcionadas para as três suturas maxilares primárias - frontomaxilar, zigomaticomaxilar, e pterigopalatina. Isto produz forças tensionais sobre a sutura frontomaxilar e

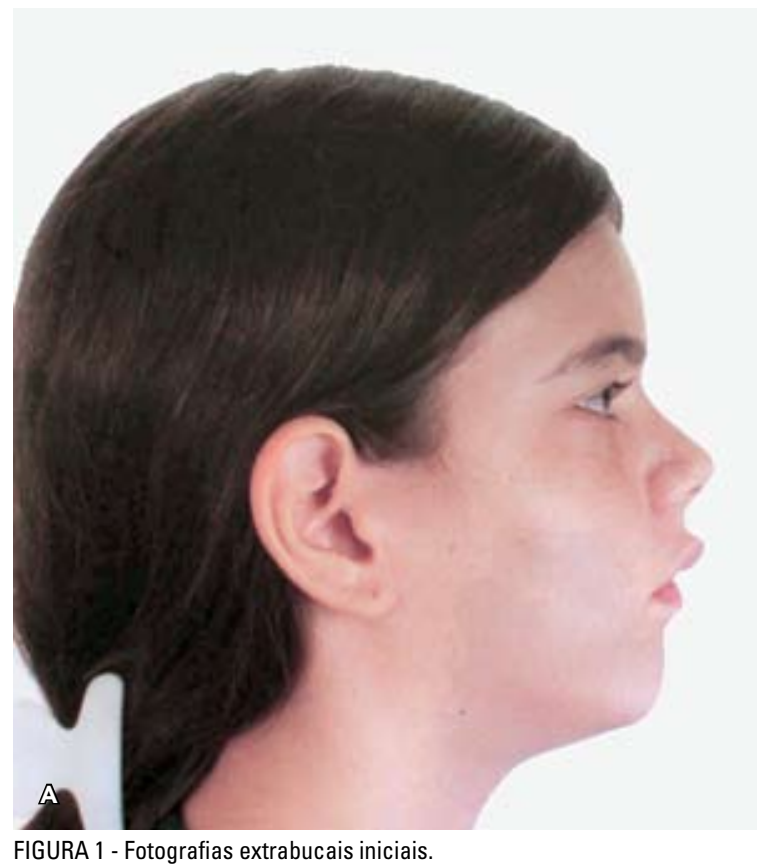

compressivas sobre a sutura pterigopalatina, que são responsáveis pela rotação horária do complexo maxilar ${ }^{9}$.

\section{RELATO DO CASO CLÍNICO}

A paciente P.V.O., leucoderma, gênero feminino, 8 anos de idade, foi encaminhada para tratamento na clínica de Ortodontia Preventiva da Faculdade de Odontologia de Ribeirão Preto-USP, tendo como queixa principal a protrusão dos incisivos centrais superiores. No exame geral foi constatado que a saúde da paciente era boa, não havia defeitos congênitos e os hábitos de higiene bucal eram satisfatórios. Ao exame clínico constatou-se assimetria facial, deglutição atípica, respiração bucal e um perfil facial convexo (Fig. 1). O exame clínico intrabucal mostrou que a paciente estava na dentadura mista com presença de mordida cruzada funcional posterior direita e um overjet acentuado ( $8 \mathrm{~mm})$. A relação molar era de Classe II, $1^{\text {a }}$ divisão, subdivisão direita (Fig. 2). A análise da dentadura mista pelo método de Moyers demonstrou discrepância ósseo dentária positiva em ambos os arcos.

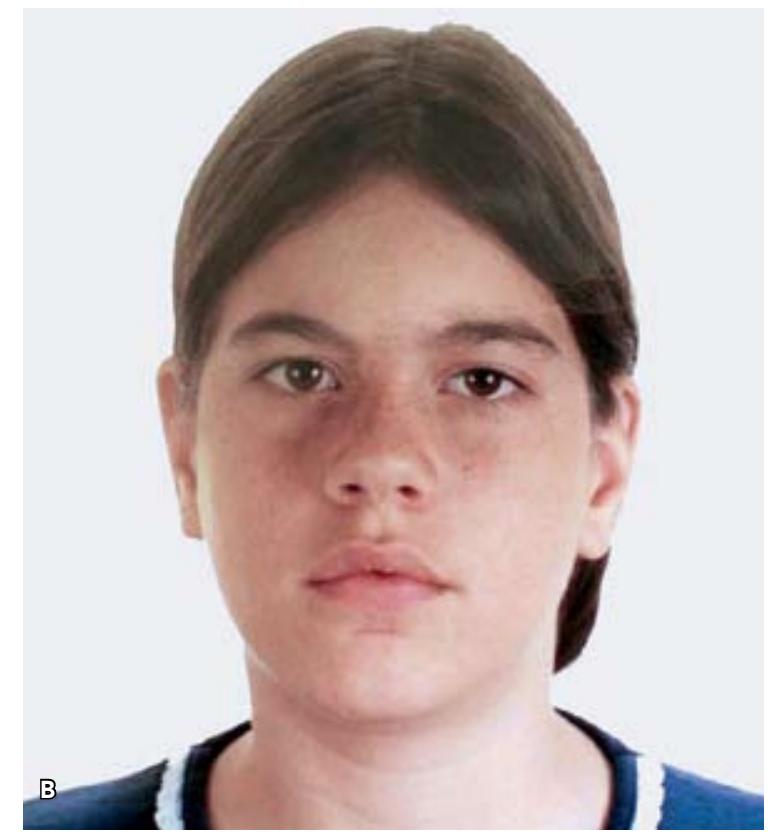



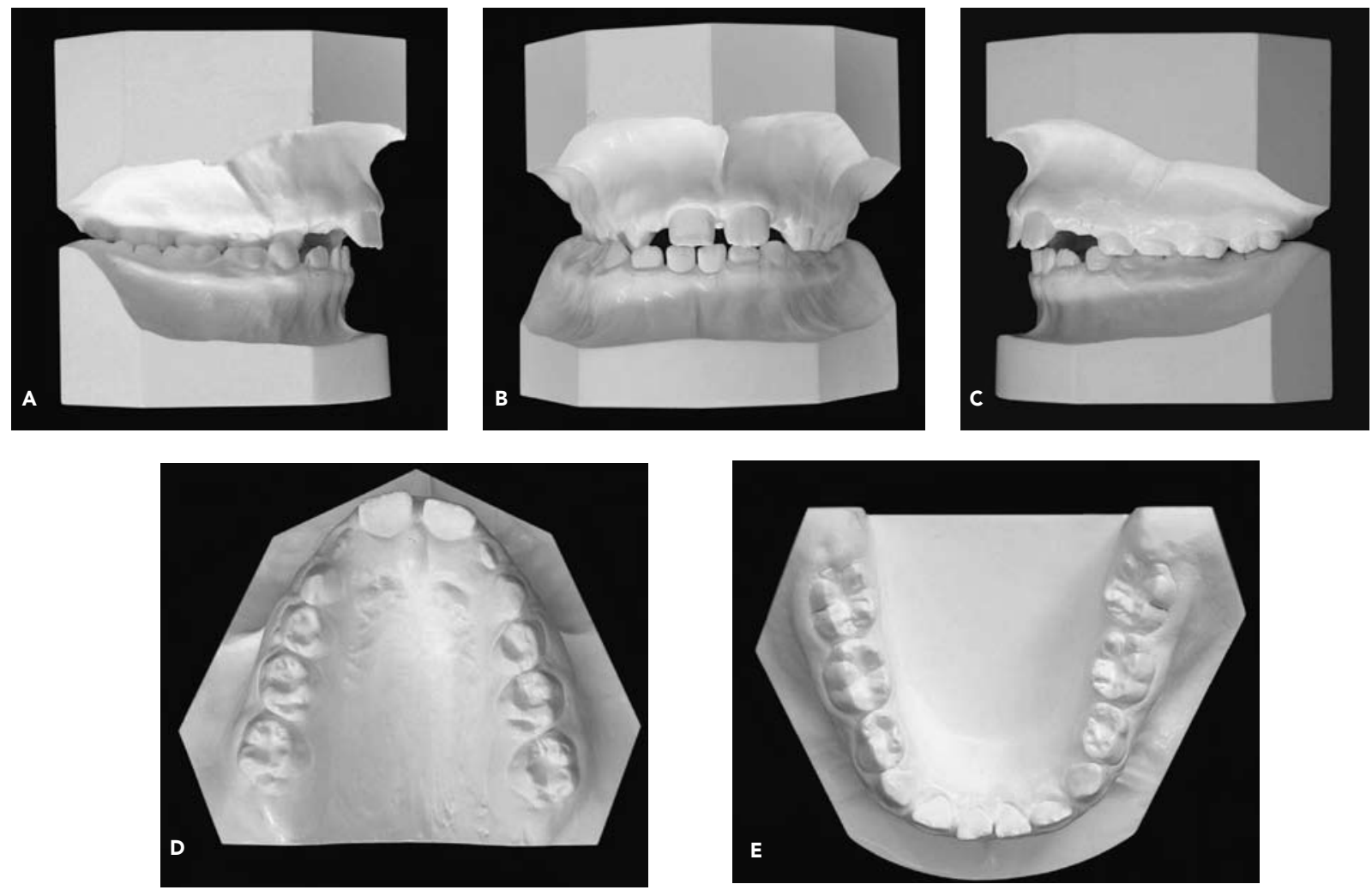

FIGURA 2 - Modelos de estudo iniciais.

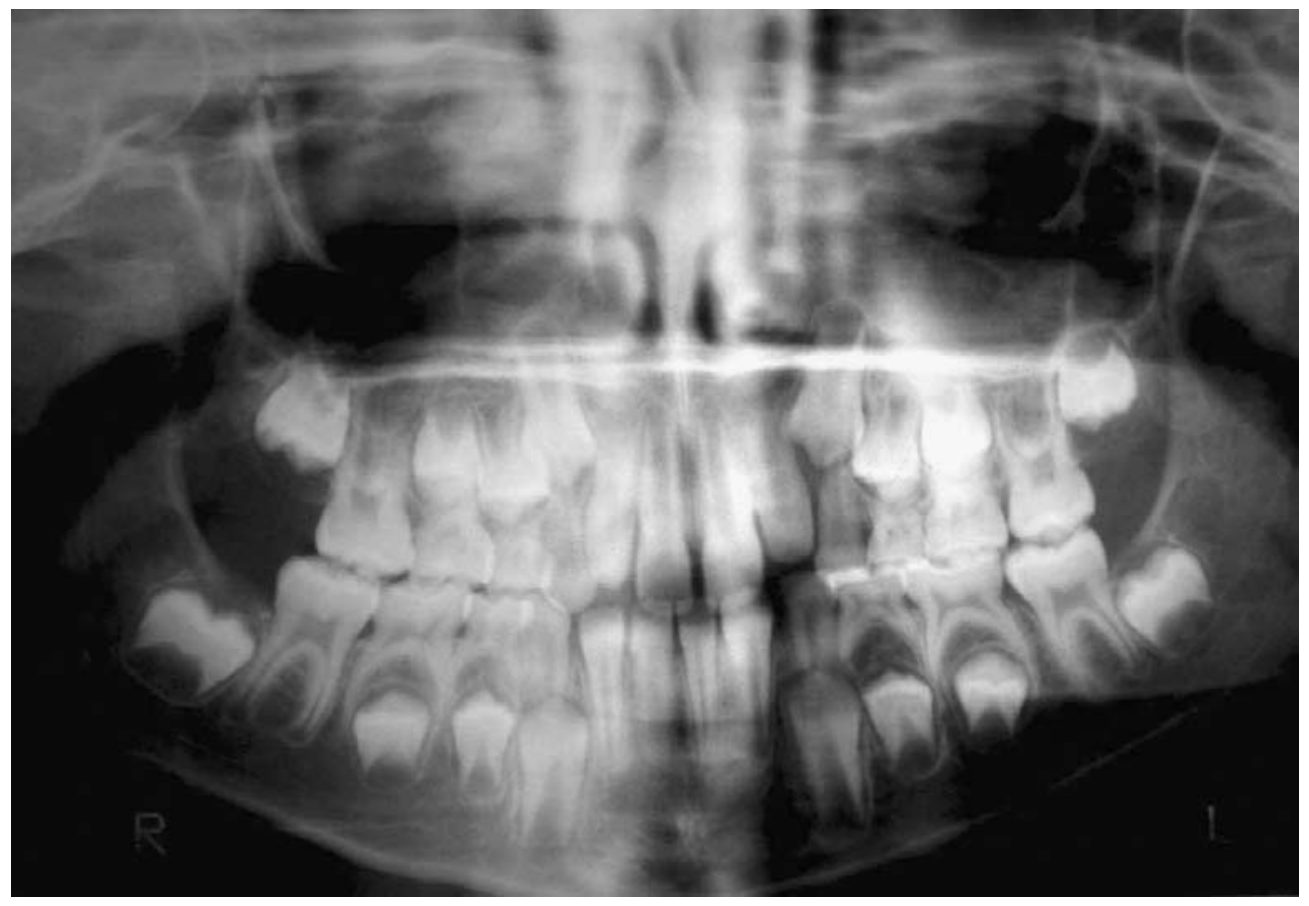

FIGURA 3 - Radiografia panorâmica inicial. 
$\mathrm{Na}$ análise da radiografia panorâmica foi verificado que o estágio de formação radicular dos dentes permanentes, assim como a seqüência e cronologia de erupção estavam normais. Os terceiros molares estavam no início de formação da cripta óssea (Fig. 3).

$\mathrm{Na}$ análise cefalométrica feita a partir da telerradiografia de perfil (Fig. 4), observou-se que a maxila estava protruída em relação à base do crânio $\left(\mathrm{SNA}=86^{\circ}\right)$ enquanto a mandíbula estava bem posicionada $\left(\mathrm{SNB}=79^{\circ}\right)$ porém estas bases não estavam bem relacionadas entre si $\left(A N B=7^{\circ}\right)$, mostrando um padrão esquelético de Classe II. A análise vertical mostrou que a paciente apresentava leve tendência ao crescimento vertical $\left(\mathrm{SNGoGn}=34^{\circ}, \mathrm{SNGn}=65^{\circ}\right.$, Eixo facial $=87^{\circ}$ ). Quanto ao padrão dentário, os incisivos superiores encontravam-se verticalizados e retruídos em relação à sua base óssea $\left(1 . \mathrm{NA}=18^{\circ}, 1-\mathrm{NA}=3 \mathrm{~mm}\right)$ e os incisivos inferiores protruídos em relação à sua base óssea $\left(1 . \mathrm{NB}=30^{\circ}, 1-\mathrm{NB}=4 \mathrm{~mm}\right)$. Na análise de perfil confirmou-se o perfil mole (em relação à linha de Steiner) e ósseo convexos (Tab. 1).

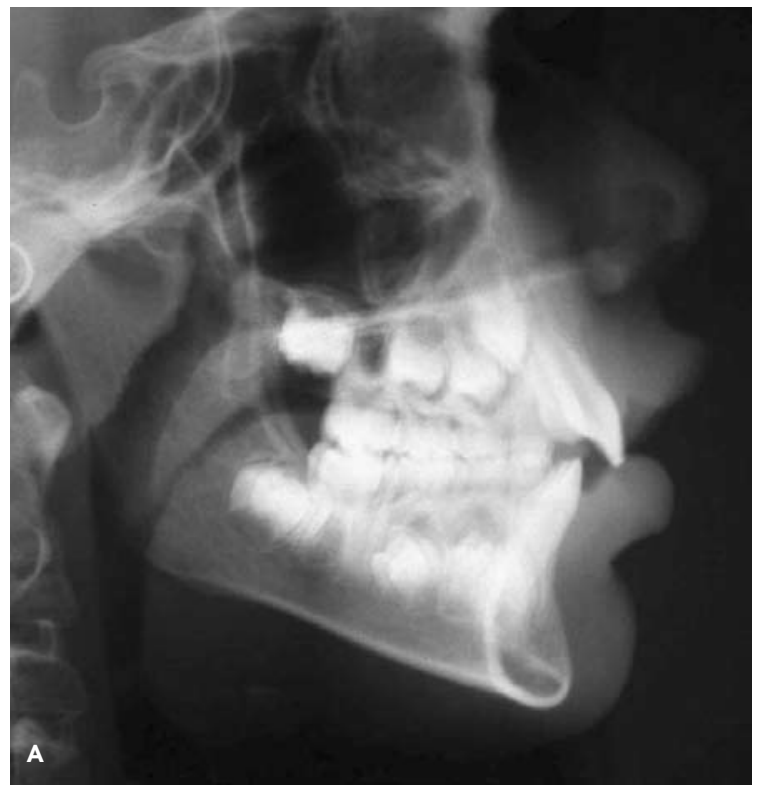

FIGURA 4 - Radiografia cefalométrica inicial com seu respectivo cefalograma

\section{Diagnóstico}

De acordo com a análise intrabucal, facial e cefalométrica, diagnosticou-se que a paciente era portadora de uma má oclusão esquelética de Classe II devido à protrusão da maxila, overjet acentuado, perfil convexo, deglutição atípica, respiração bucal e mordida cruzada posterior funcional.

\section{Objetivos do tratamento}

Correção da relação maxilo-mandibular ântero-posterior e transversal.

\section{Plano de tratamento}

Para a obtenção de resultados satisfatórios optou-se pelo tratamento dividido em três fases:

- $1^{\text {a }}$ Fase: Instalação de um aparelho removível com parafuso expansor com grade (Fig. 5) assim como desgaste das interferências oclusais na região de caninos decíduos, para corrigir a mordida cruzada posterior e interceptar os hábitos. Nesta fase a paciente também foi encaminhada ao tratamento fonoaudiológico.

- $2^{a}$ Fase: Instalação do aparelho extrabucal original de Thurow (Fig. 6), com direção da tração

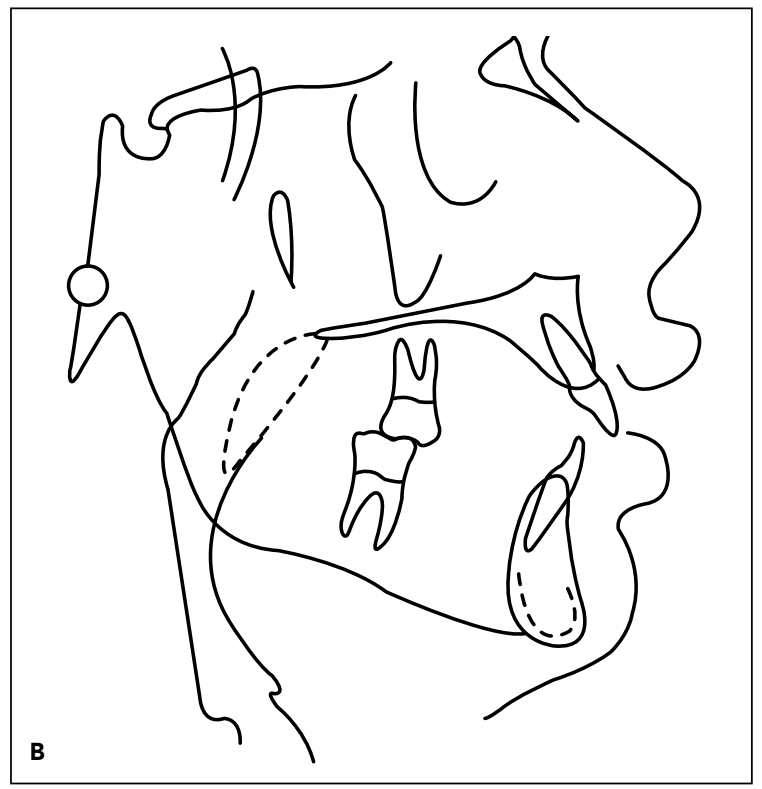




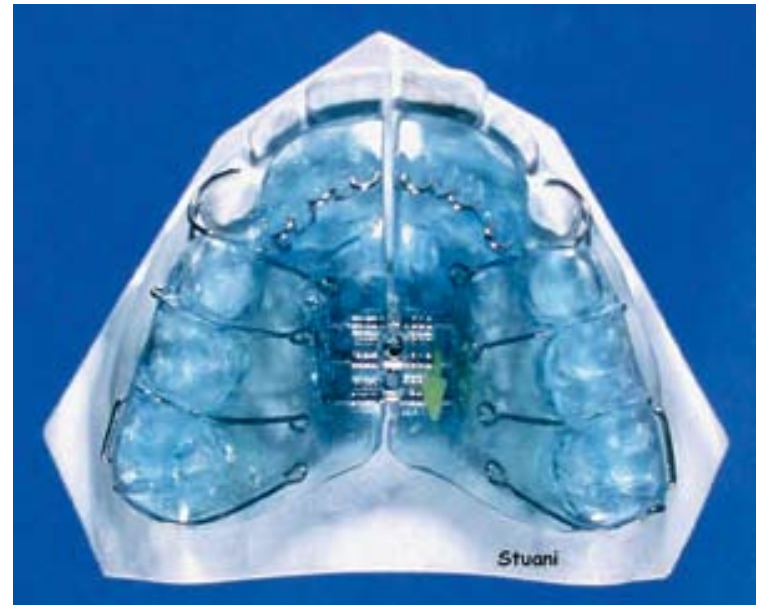

FIGURA 5 - Aparelho removível superior com grade vertical e parafuso expansor.

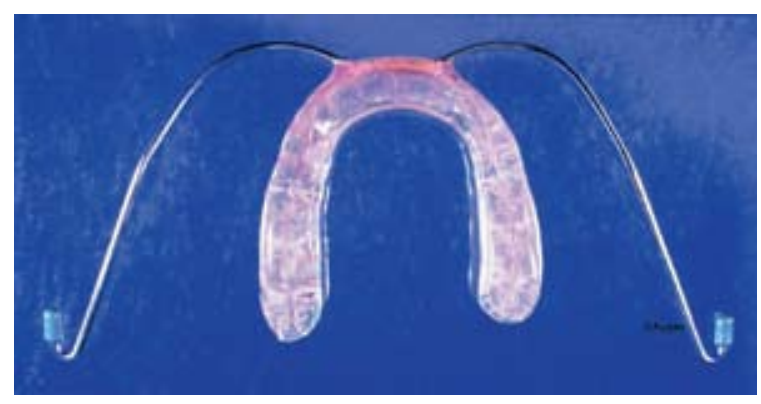

FIGURA 6 - Aparelho de Thurow.

para cima e para trás (Fig. 7).

- $3^{\text {a }}$ Fase: Indicar para Ortodontia corretiva para o alinhamento e nivelamento dos dentes, caso haja necessidade.

\section{Tratamento}

O tratamento foi iniciado, conforme planejado, com a instalação do aparelho removível com parafuso expansor com grade vertical anterior (Fig. 5) onde o parafuso era ativado $1 / 4$ de volta por semana, sendo utilizado por seis meses, promovendo o descruzamento da mordida na região de molares e auxiliando o fonoaudiólogo na eliminação dos hábitos bucais. Seguiu-se então a instalação do aparelho extrabucal de Thurow (Fig. 6). A fim de se obter um maior controle da força aplicada, o arco externo do extrabucal foi dobrado na altura dos $1^{\text {os }}$ molares permanentes superiores e foi leve- mente angulado para cima proporcionando uma força para trás e para cima (Fig 7). Dessa forma, a força gerada pelo elástico passava próximo ao centro de resistência da maxila, na região da tuberosidade, com a finalidade de restringir o crescimento vertical da mesma. Foi usado elástico $1 / 2 \mathrm{P}$ (Morelli) que proporcionou uma força de 500gr. de cada lado e a paciente foi orientada a trocar os elásticos a cada semana. Foi indicado o uso do aparelho por período integral.

Um ano após o início do tratamento com o aparelho de Thurow observou-se resultados satisfatórios e, a partir daí, foi indicado seu uso apenas durante a noite como contenção, sendo utilizado por mais 12 meses. A erupção dos dentes permanentes da paciente foi acompanhada através de consultas regulares, não sendo necessária a utilização de nenhum outro tipo de aparelho neste período.

Após 2 anos de uso do aparelho de Thurow, obteve-se uma relação molar e canino de Classe I e redução acentuada do overjet (Fig.8). Numa vista oclusal superior observa-se a presença de diastemas na mesial dos molares devido à inclinação distal deste dente (Fig. 8). No arco inferior todos os dentes permanentes irromperam bem posicionados com exceção dos segundos pré-molares que ainda estão intra-ósseos (Fig. 9).

A radiografia panorâmica final mostrou a presença de todos os dentes permanentes inclusive os germes dos terceiros molares. Os segundo pré-molares inferiores estão na fase final da rizogênese (Fig. 9).

$\mathrm{Na}$ análise cefalométrica final (Fig. 10) a maxila $\left(\mathrm{SNA}=83^{\circ}\right)$ e a mandíbula $\left(\mathrm{SNB}=79^{\circ}\right)$ estavam bem posicionadas em relação à base do crânio e entre si $\left(\mathrm{ANB}=4^{\circ}\right)$. O padrão de crescimento facial ainda continuou no sentido horário $\left(\mathrm{SNGoGn}=35^{\circ}, \mathrm{SNG}=69^{\circ}\right.$, Eixo Facial $\left.=82^{\circ}\right)$. Os incisivos superiores foram inclinados para palatina $\left(1 . \mathrm{NA}=6^{\circ}\right.$ e $\left.1 . \mathrm{NA}=1 \mathrm{~mm}\right)$, enquanto que os inferiores mantiveram sua posição inicial. $\mathrm{O}$ perfil ósseo e mole ainda se apresentaram convexos porém melhor relacionados do que inicialmente (Tab. 1).

A sobreposição total dos traçados cefalomé- 

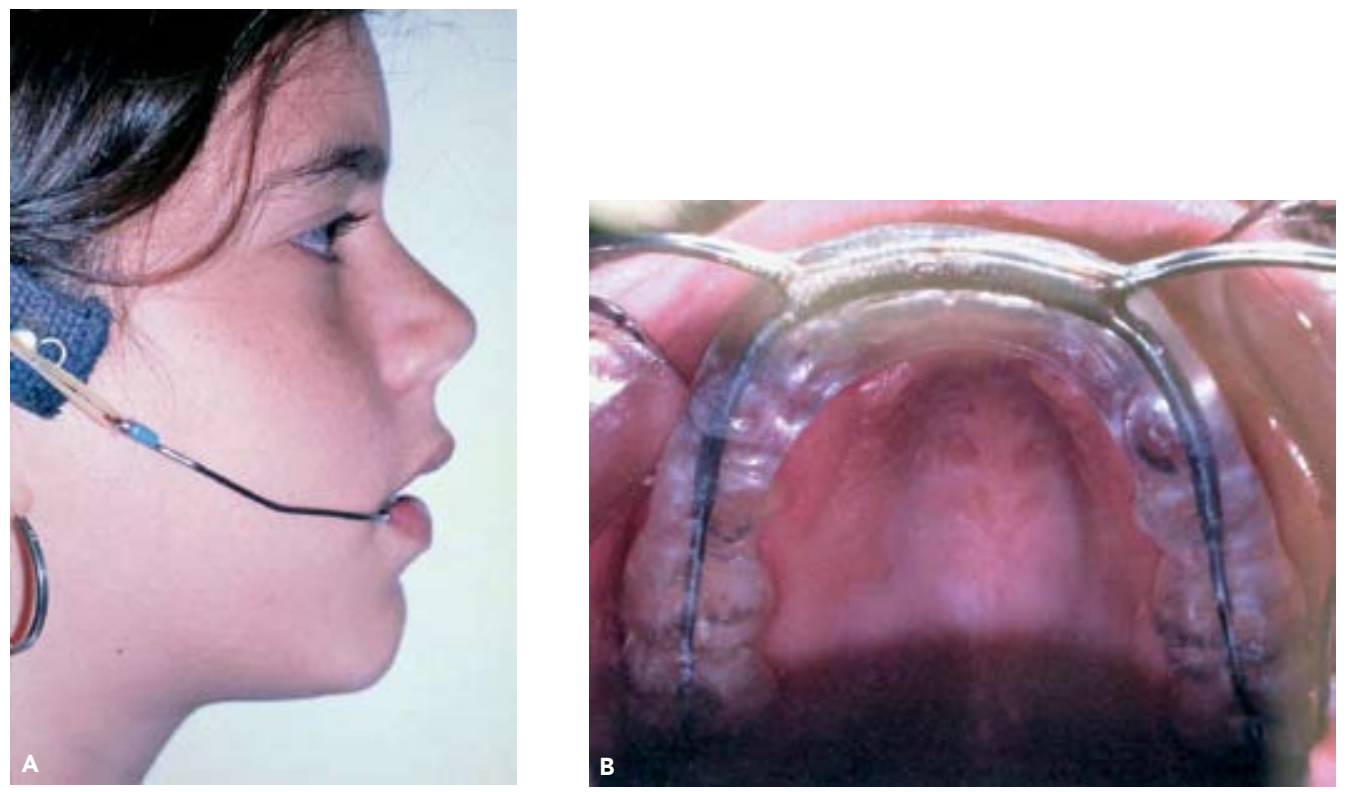

FIGURA 7 - Aparelho de Thurow instalado.
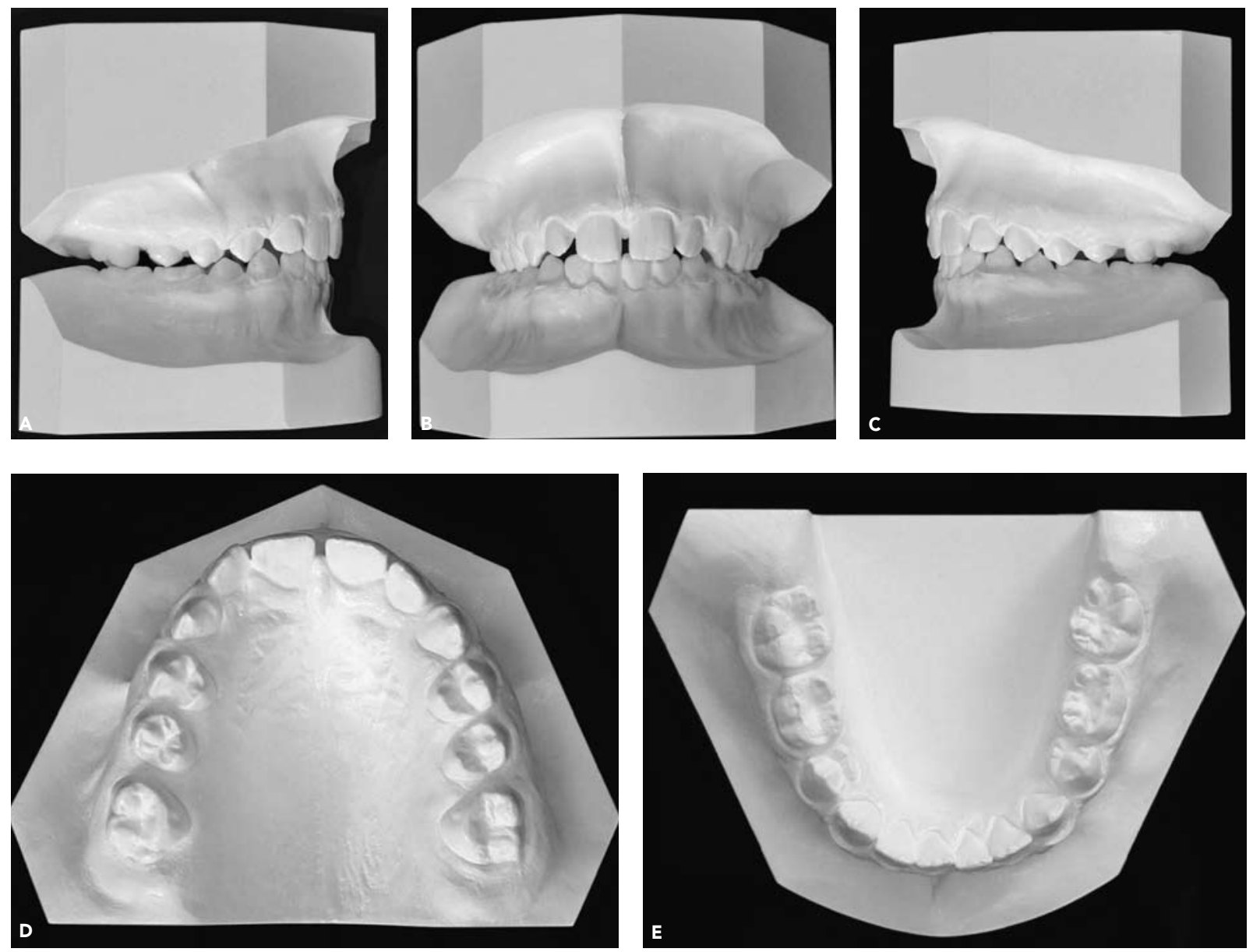

FIGURA 8 - Modelos de estudo finais. 


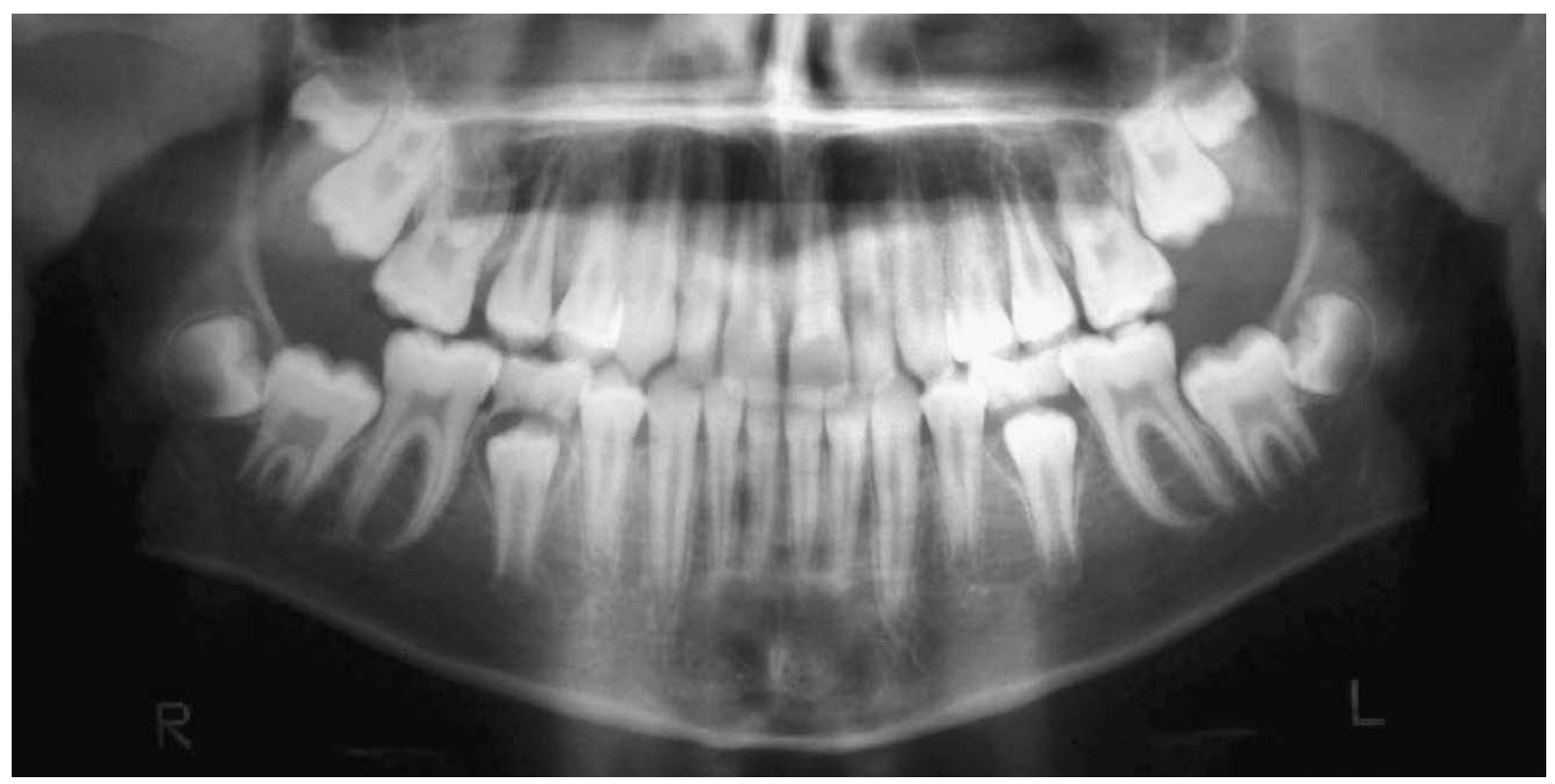

FIGURA 9 - Radiografia panorâmica final.

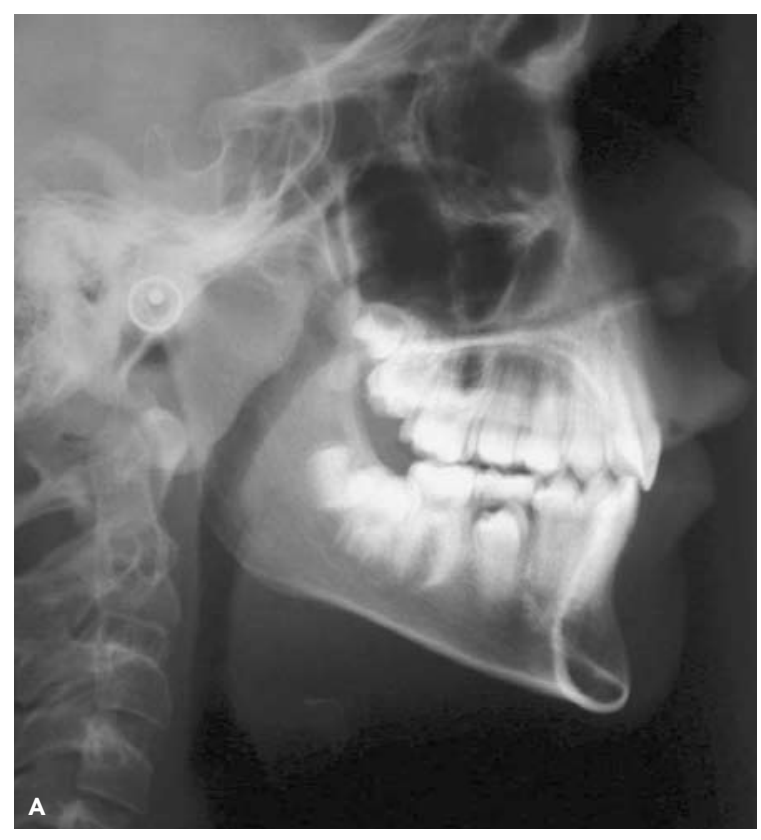

FIGURA 10 - Radiografia cefalométrica final com seu respectivo cefalograma.

tricos inicial e final (Fig. 11) mostrou que houve restrição do crescimento maxilar tanto no sentido vertical quanto no ântero-posterior, enquanto que a mandíbula projetou-se mais para baixo do que no sentido ântero-posterior, ou seja, no mesmo

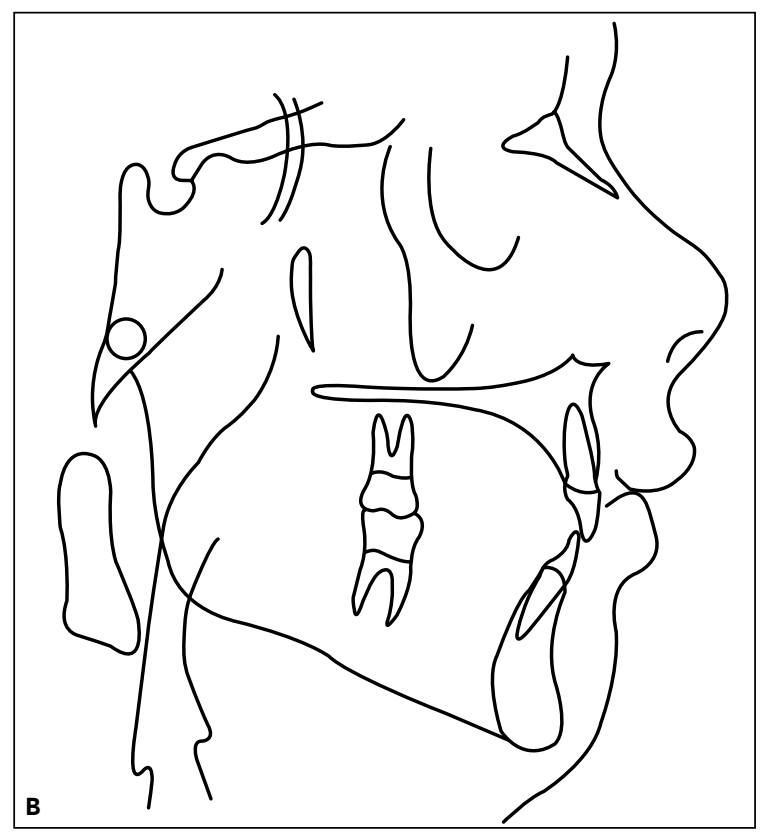

sentido do crescimento normal.

A sobreposição parcial da maxila mostrou que esta girou levemente no sentido horário e houve um pequeno crescimento na ENA e ENP (Fig.12). A sobreposição parcial da mandíbula mostrou um 


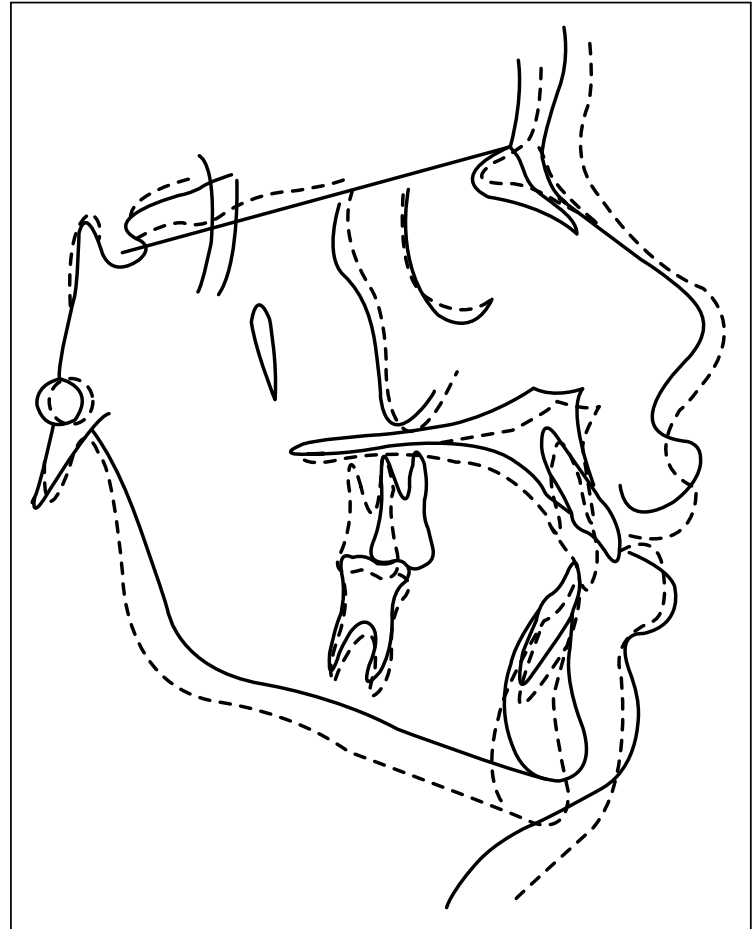

FIGURA 11 - Sobreposição total dos traçados cefalométricos.

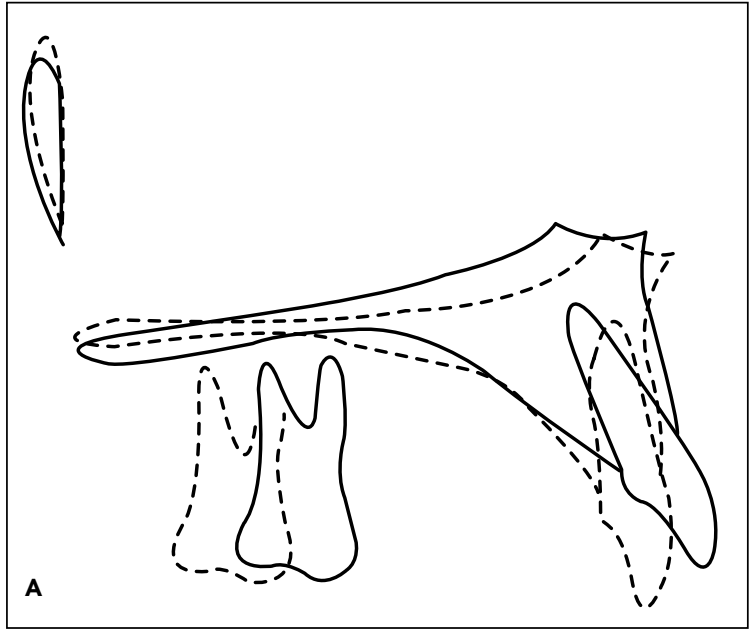

FIGURA 12 - Sobreposição total da maxila.

crescimento vertical mais acentuado. O crescimento horizontal foi mascarado pela rotação da mandíbula no sentido horário (Fig.13).

A sobreposição parcial da maxila sobre o plano
Tabela 1 - Valores cefalométricos iniciais e finais.

\begin{tabular}{|c|c|c|}
\hline NORMA & 7a. $11 \mathrm{~m}$. & $11 a$. \\
\hline $\mathrm{SNA}=82^{\circ}$ & $S N A=86^{\circ}$ & $S N A=83^{\circ}$ \\
\hline SNB $=80^{\circ}$ & $S N B=79^{\circ}$ & $S N B=79^{\circ}$ \\
\hline $\mathrm{ANB}=4^{\circ}$ & $\mathrm{ANB}=7^{\circ}$ & $\mathrm{ANB}=4^{\circ}$ \\
\hline $\operatorname{SnGoGn}=32^{\circ}$ & $\operatorname{SnGoGn}=34^{\circ}$ & $\mathrm{SnGoGn}=35^{\circ}$ \\
\hline $\mathrm{SnGn}=67^{\circ}$ & $\mathrm{SnGn}=65^{\circ}$ & $\mathrm{SnGn}=69^{\circ}$ \\
\hline xo Facial $=90^{\circ}$ & Eixo Facial $=87^{\circ}$ & Eixo Facial $=82^{\circ}$ \\
\hline $1 . N A=22^{\circ}$ & $1 . N A=18^{\circ}$ & $1 . N A=6^{\circ}$ \\
\hline $1-\mathrm{NA}=4 \mathrm{~mm}$ & $1-\mathrm{NA}=3 \mathrm{~mm}$ & $1-\mathrm{NA}=1 \mathrm{~mm}$ \\
\hline $1 . N B=25^{\circ}$ & $1 . N B=30^{\circ}$ & 1.NB $=30^{\circ}$ \\
\hline $1-N B=4^{\circ}$ & $1-\mathrm{NB}=4 \mathrm{~mm}$ & $1-\mathrm{NB}=4 \mathrm{~mm}$ \\
\hline Pog $=-8,5^{\circ}+10^{\circ}$ & NAPog $=13^{\circ}$ & NAPog $=11^{\circ}$ \\
\hline $\mathrm{S}-\mathrm{Ls}=0 \mathrm{~mm}$ & $S-L s=6 m m$ & $S-L s=4 m m$ \\
\hline $\mathrm{S}-\mathrm{Li}=0 \mathrm{~mm}$ & $\mathrm{~S}-\mathrm{Li}=4 \mathrm{~mm}$ & $S-L i=1 \mathrm{~mm}$ \\
\hline
\end{tabular}

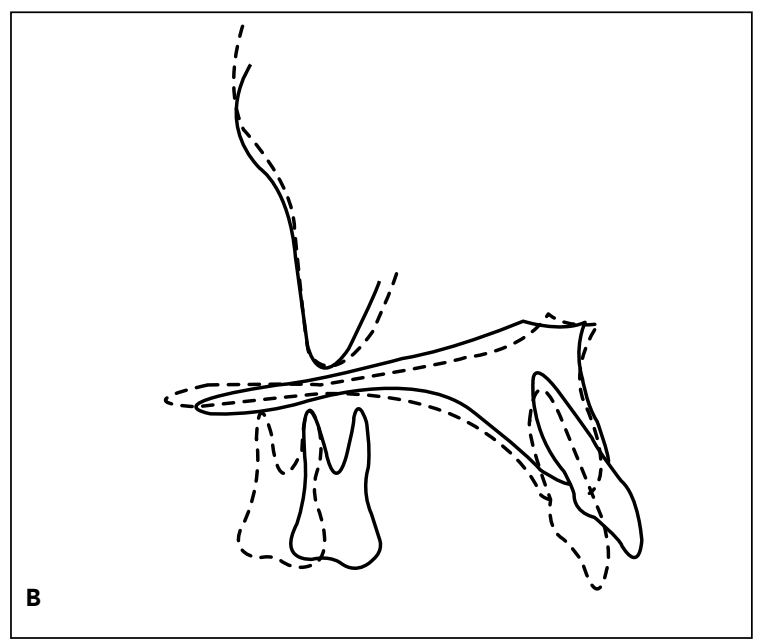

palatino para verificar a movimentação dentária mostrou que tanto o molar quanto o incisivo foram distalizados e extruídos (Fig. 14). Esta extrusão foi devida ao crescimento vertical da maxila. 


\section{DISCUSSÃO}

Para a correção da má oclusão esquelética de Classe II, a terapia com forças ortopédicas tornase necessária ${ }^{20}$. A terapia ortodôntica tem como objetivo a correção da má oclusão dentoalveolar, sem nenhum desvio esquelético, visando apenas o movimento dentário ${ }^{21}$. A maioria dos autores ${ }^{7,11}$, $14,17,23,27$ acredita que a quantidade de força aplicada na maxila por uma tração extrabucal deveria estar entre 400 a 800 gramas e, mesmo não sendo esta quantidade essencialmente "ortopédica", está diretamente relacionada ao desconforto dentário produzido por forças mais pesadas.

Forças extrabucais pesadas têm produzido clinicamente um efeito rápido e intenso na maxila e dentição maxilar ${ }^{1,13,26}$. Graber $^{7}$ afirma que quanto maior a força aplicada no osso basal, mais ortopédica é sua natureza. Este autor destacou que o sucesso das mudanças no tratamento ortodôntico utilizando ancoragem extrabucal ocorria quando o mesmo era executado na época de maior crescimento puberal ${ }^{7}$.

Pacientes jovens são mais motivados e cooperativos em relação à terapia com tração extrabucal e este é um fato de grande importância, já que evidências clínicas sugerem que máximas mudanças ortopédicas/ortodônticas são alcançadas por aqueles pacientes que usam seus aparelhos quase

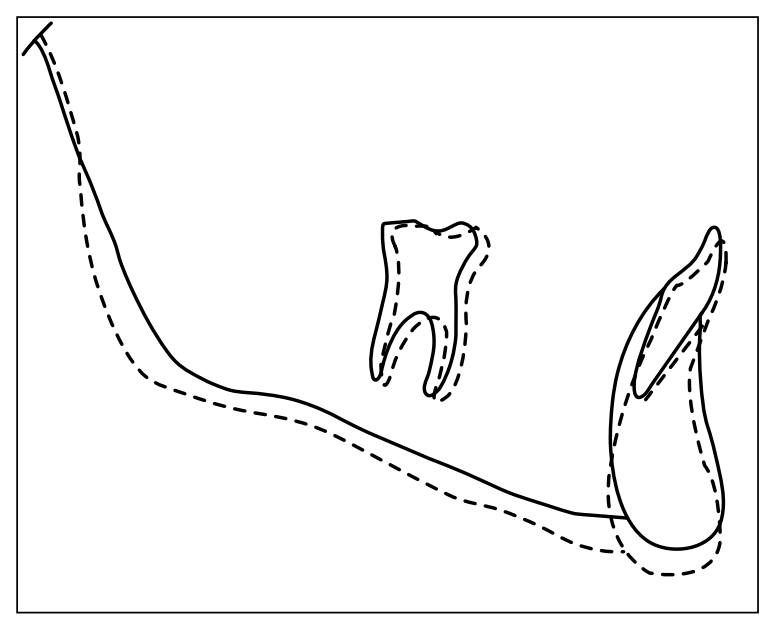

FIGURA 13 - Sobreposição total da mandíbula. continuamente. O grau de correção ou mudança ântero-posterior está mais relacionado ao número de horas por dia no qual o aparelho é usado do que ao tempo total de tratamento ${ }^{10,18,19}$.

Assim, quando o tratamento é iniciado precocemente, tem-se a vantagem de aproveitar ao máximo o crescimento das bases ósseas ${ }^{18,19}$. Além disso, diminui-se o risco de trauma sobre os incisivos superiores, que se encontram protruídos na má oclusão esquelética de Classe II, e pode-se contar com maior cooperação do paciente no uso de aparelhos extrabucais do que quando este chegar à adolescência.

Utilizando um aparelho funcional e tração extrabucal em dois grupos distintos comparados a um grupo controle que não recebeu nenhum tipo de tratamento, Tulloch ${ }^{24}$ concluiu que o tratamento precoce da má oclusão esquelética de Classe II moderada a severa, não produziu grandes diferenças no relacionamento intermaxilar ou na oclusão, diferentemente demonstrado no presente caso clínico onde se observou uma melhora no relacionamento inter-maxilar e na redução do overjet apresentado pela paciente.

Thurow $^{23}$, assim como Graber ${ }^{7}$, recomenda o uso do AEB durante 12 horas por dia utilizando como justificativa o fato dos picos de crescimento ocorrerem durante o sono. Por outro lado,

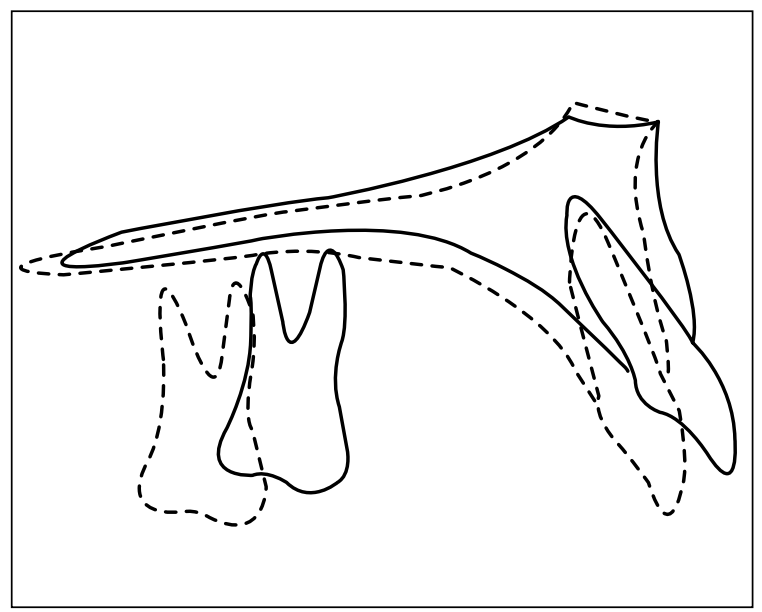

FIGURA 14 - Sobreposição parcial da maxila mostrando o movimento dentário dos molares e dos incisivos molares e dos incisivos. 
Armstrong ${ }^{1}$ e Watson ${ }^{26}$ defendem o uso de força contínua, assim como Caldwell et al. ${ }^{5}$, que afirmam que os pacientes sempre utilizam o aparelho por tempo menor do que o recomendado.

Vários tipos de aparelhos extrabucais acoplados a aparelhos removíveis foram propostos na literatura para corrigir a má oclusão esquelética de Classe II. Todos estes aparelhos têm em comum, o intuito de promover um efeito de controle vertical do crescimento da maxila, o que já provou ser um importante fator no tratamento das discrepâncias sagitais, como a Classe II. Caldwell et al. ${ }^{5}$ sugeriram o uso do splint maxilar associado à tração alta em pacientes com síndrome da face longa devido ao controle sobre o crescimento vertical exibido sobre a maxila.

Henriques et al. ${ }^{9}$ descreveram o splint maxilar modificado composto por uma placa de acrílico que se estendia lateralmente às cúspides vestibulares dos dentes posteriores e anteriormente às superfícies palatinas dos incisivos. Segundo estes autores o acrílico deveria ser o mais fino possível para evitar qualquer translação dos côndilos ou aumentar a altura facial inferior. Foi proposto, também a colocação de um torno expansor ao nível dos segundos molares decíduos para permitir ajustes laterais dos segmentos posteriores, evitando o desenvolvimento da mordida cruzada posterior. $\mathrm{O}$ arco extrabucal apresentava-se embutido no acrílico na região dos molares decíduos. A fim de aumentar a retenção do aparelho os autores acrescentaram um arco vestibular de Hawley e grampos de Adams.

Yokota et al. ${ }^{30}$ associaram a tração alta com arco extrabucal a um aparelho funcional removível com $\mathrm{o}$ intuito de promover um crescimento anterior da mandíbula. Bernstein ${ }^{4}$ utilizou força extrabucal associada a um aparelho removível maxilar, obtendo apenas movimento dentário.

Teuscher ${ }^{22}$ defende a utilização do aparelho ativador combinado à tração alta posterior, onde o arco se encaixa no ativador, afirmando ser possível aproveitar ao máximo o crescimento condilar no plano sagital, havendo uma melhora no perfil facial graças ao desenvolvimento anterior da mandíbula, afirmando ser possível o controle da direção de crescimento durante o tratamento. Segundo o autor, a localização do centro de resistência da maxila está situado na área póstero-superior da sutura zigomaticomaxilar. O prognóstico da reação à aplicação da força é feito de acordo com a direção desta em sua relação a este centro de resistência ${ }^{16}$.

O uso do splint maxilar, descrito por Thurow ${ }^{23}$, em pacientes jovens com má oclusão severa de Classe II tem como vantagem a redução da vulnerabilidade dos incisivos superiores à ocorrência de fraturas, reduzindo concomitantemente a displasia esquelética, portanto diminuindo o período de correção ortodôntica corretiva. Outras vantagens são a fácil confecção e a sua aplicação clínica, o que o torna um aparelho atrativo em clínicas ou instituições que têm como preocupação principal o volume de pacientes, a freqüência de visitas e os fatores econômicos ${ }^{10}$. No caso apresentado, pôde ser observado um controle da maxila tanto no sentido vertical como ântero-posterior, conseguido devido à aplicação de tração alta e do direcionamento da força de forma a passar próxima ao centro de resistência da maxila.

Normalmente uma segunda fase objetivando um perfeito alinhamento dos dentes e uma finalização satisfatória do tratamento pode ser necessária, entretanto, esta segunda fase será mais rápida e fácil uma vez que as discrepâncias esqueléticas já foram corrigidas ou amenizadas durante a primeira fase o que torna este tipo de tratamento bastante atrativo.

\section{CONCLUSÃO}

Em pacientes em fase de crescimento, a aplicação de força extrabucal na maxila, por meio do splint maxilar, é um método eficaz para a correção inicial da má relação ântero-posterior da maxila e mandíbula. $\mathrm{O}$ efeito mais expressivo é a correção da má oclusão esquelética de Classe II. 
O overbite e, principalmente o overjet podem ser substancialmente reduzidos, de maneira rápida, em pacientes cooperativos. O presente relato mostrou que o aparelho de Thurow constitui uma ótima alternativa para o tratamento ortopédico das discrepâncias ósseas presentes na má oclusão esquelética de Classe II, previamente a uma terapia ortodôntica com aparelho fixo.

Enviado em: Abril de 2004 Revisado e aceito: Julho de 2004

\section{The use of Thurow's appliance in the treatment of skeletal class II malocclusion \\ Abstract \\ The aim of this study was to review the literature concerning the treatment of Class II malocclusion with removable maxillary splint associated to the high traction, enhancing its influence in the bony growth and its benefits. This clinical case will show the fabrication and the effects of Thurow's appliance, when it's used in the mixed dentition for the correction skeletal class II malocclusion.}

Key words: Class II. High pull. Maxillary splint

\section{REFERÊNCIAS}

1. ARMSTRONG, M. M. Controlling the magnitude, direction and duration of extraoral force. Am J Orthod, St. Louis, v. 59, p. 217, 1971.

2. BALLARD, C. F. An orthodontic review of occlusions in relation to periodontal problems. Dent Pract, Bristol, v. 3, p. 311-320, 1953.

3. BASS, N. M. Orthopedic coordination of dentofacial development in skeletal Class II malocclusion in conjunction with edgewise therapy. Part I. Am J Orthod, St. Louis, v. 84, no. 5, p. 361-383, Nov. 1983.

4. BERNSTEIN, L.; ULBRICH, R. W.; GIANELLY, A. A. Orthopedics versus orthodontics in Class II treatment: an implant study. Am J Orthod, St. Louis, v. 72, no. 5, p. 549-559, Nov. 1977.

5. CALDWELL, S. F.; HYMAS, A.; TIMM, T. A. Maxillary traction splint: a cephalometric evaluation. Am J Orthod, St. Louis, v. 85, no. 5, p. 376-384, May 1984.

6. DUGONI, S. A.; LEE, J. S.; VARELA, J.; DUGONI, A. A. Early mixed dentition treatment: postretention evaluation of stability and relapse. Angle Orthod, Appleton, v. 65, p. 311-320, 1995.

7. GRABER, T. M.; SWAIN, B. F. Current orthodontic concepts and techniques. 2 nd ed. Philadelphia: W. B. Saunders, 1975. p. $365-452$.

8. HASS, A. J. Palatal expansion: Just the beginning of dentofacial orthopedics. Am J Orthod, St. Louis, v. 57, p. 219-255, 1970.

9. HENRIQUES, J. F. C.; MARTINS, D. R.; ALMEIDA, G. A. Modified maxillary splint for class II, division 1 treatment. JCO, Boulder, v. 25, no. 4. p. 239-245, Apr. 1991.

10. JOFFE, L.; JACOBSON, A. The maxillary orthopedic splint. Am J Orthod, St. Louis, v. 75, no. 1. p. 54-69, Jan. 1979.

11. KING, E. W. Cenvical anchorage in Class II, Division 1 treatment: a cephalometric appraisal, Angle Orthod, Appleton, v.27, p.98, 1957.

12. KLOEHN, S. J. Orthodontics- force or persuation. Angle Orthod, Appleton, v. 23, p. 56-65, 1953.

13. MILLS, C. M.; HOLMAN, R. G.; GRABER, T. M. Heavy intermittent cervical traction in Class II treatment; a longitudinal cephalometric assessment. Am J Orthod, St. Louis, v. 74, p. 361-379, 1978.

14. MOORE, A. W. Orthodontic treatment factors in Class II malocclusion. Am J Orthod, St. Louis, v. 45, p. 323, 1959.

15. MOYERS, R. E. Ortodontia. 4. ed. Rio de Janeiro: CID, 1988.

16. NANDA, R. Biomechanics in the Clinical Orthodontics. Philadelphia: W. B. Saunders Company, 1997.
17. POULTON, D. R. The influence of extraoral traction. Am J Orthod, St. Louis, v. 53, p. 8-18, 1967.

18. RICKETTS, R. M. The influence of orthodontic treatment on facial growth and development. Angle Orthod, Appleton, v. 30, p.103-131, 1960.

19. SADOWSKY, P. L. Craniofacial growth and the timing of treatment. Am J Orthod Dentofacial Orthop, St. Louis, v.113, no. 1, p. 19-23, Jan. 1998.

20. SASSOUNI, V. Dentofacial orthopedics: a critical review. Am J Orthod, St. Louis, v. 61, p. 225- 269, 1972.

21. STARNES, L. O. Dentofacial orthopedics: when and how? PCSO Bull, [S.I.], v. 68, p. 37-38, 1996.

22. TEUSCHER, U. A growth-related concept for skeletal Class II treatment. Am J Orthod, St. Louis, v. 74, no. 3, p. 258-275, Sept. 1978.

23. THUROW, R. C. Craniomaxillary orthopedic correction with em mass dental control. Am J Orthod, St. Louis, v. 68, no. 6, p. 601-623, Dec. 1975.

24. TULLOCH, J. F. C.; PHILIPS, C.; PROFFIT, W. R. Benefit of early Class II treatment: Progress report of a two-phase randomized clinical trial. Am J Orthod Dentofacial Orthop, St. Louis, v.113, no.1, p. 62-72, Jan. 1998.

25. TWEED, C. H. Clinical orthodontics. St. Louis: C. V. Mosby, 1966.

26. WATSON, W. G. A computadorized appraisal of the high-pull face-bow. Am J Orthod, St. Louis, v. 62, p. 561, 1972.

27. WIESLANDER, L. The effect of force on craniofacial development. Am J Orthod, St. Louis, v. 65, p. 531, 1974.

28. WIESLANDER, L. The effect of orthodontic treatment on the concurrent development of the craniofacial complex. Am J Orthod, St. Louis, v. 49, p. 15-27, 1963.

29. WOODSIDE, D. G. Umpublished manuscript. Quoted in Graber, T.M. Orthodontics: principles and practice. 3rd ed. Philadelphia: W. B. Saunders, 1969

30. YOKOTA, S.; MURAKAMI, T.; SHIMIZU, K. A growth control approach to Class II, division 1 cases during puberty involving the simultaneous application of maxillary growth restriction and mandibular forward induction. Am J Orthod Dentofacial Orthop, St. Louis, v.104, no. 3, p. 211-223, Sept. 1993.

\section{Endereço para correspondência}

Maria Bernadete Sasso Stuani

Faculdade de Odontologia de Ribeirão Preto - SP

Av. do Café, $s / n$

CEP: 14.040-904 - Ribeirão Preto/SP

E-mail: bernadete@fop.usp.br 